\title{
Analisis Image Likes to Followers Ratio Instagram Pada 5 Perusahaan Game Asal Indonesia Yang Mendunia
}

\author{
Muhammad Tengku Rizky \\ STIMIK STIKOM Indonesia \\ anountengku@gmail.com
}

\begin{abstract}
ABSTRAK
Instagram adalah platform media sosial yang lahir dari sebuah perusahaan bernama Burbn, Inc. yang berdiri pada 6 oktober 2010. Perusahaan ini sendiri didirikan oleh Kevin Systrom dan Mike Krieger. Aplikasi ini memiliki berbagai macam fitur seperti fitur reels, live streaming, posting gambar, filter, dll. Hingga kuratal awal 2021, jumlah pengguna aktif instagram di seluruh dunia sudah mencapai sekitar 1.07 miliar pengguna dan 354 juta penggunanya berusia 25 hingga 34 tahun. Banyak juga perusahaan-perusahaan yang mencari peluang dalam mempromosikan jasa ataupun krediblitas perusahaan mereka melalui instagram. Sebagai contohnya adalah 5 Perusahaan Game Asal Indonesia Yang Mendunia. Adapun tujuan dari penelitian ini adalah, untuk menghitung kredebilitas dari performa akun instagram 5 Perusahaan Game Asal Indonesia. Metode yang digunakan dalam penelitian ini adalah metode eksplorasi kuantitatif. Hasil dari penelitian diharapkan dapat mendapatkan peringkat dari masing-masing akun tersebut.
\end{abstract}

\begin{abstract}
Instagram is a social media platform that was born from a company called Burbn, Inc. which was founded on October 6, 2010. The company itself was founded by Kevin Systrom and Mike Krieger. This application has various features such as reels, live streaming, image posting, filters, etc. Until early 2021, the number of active Instagram users worldwide has reached around 1.07 billion users and 354 million users aged 25 to 34 years. Many companies are also looking for opportunities to promote their services or company credibility through Instagram. For example, 5 Game Companies from Indonesia that are Worldwide. The purpose of this study is to calculate the credibility of the Instagram account performance of 5 Indonesian Game Companies. The method used in this study is a quantitative exploration method. The results of the research are expected to be able to get a rating from each of these accounts.
\end{abstract}

Keyword : what is instagram ? total instagram user at Q1 2021, 5 perusahaan game asal indonesia yang mendunia. 


\section{A. PENDAhULUAN}

Era Teknologi Informasi dan Komunikasi semakin berkembang pesat.

Dahulu saat awal-awal era teknologi informasi dan komunikasi, kita menggunakan telegram sebagai media komunikasi. Sekarang, kita menggunakan media sosial seperti whatsapp, instagram, youtube,tiktok, dll sebagai media komunikasi. Dengan berkembangnya Teknologi Informasi dan Komunkasi, dengan lahirnya media sosial seperti instagram, whatsapp, dll, maka ini sangat menguntungkan semua, baik mereka dari industri maupun perorangan.

Salah satu contoh dari media sosial adalah Instagram. Instagram sendiri adalah sebuah media sosial yang dimana memungkinkan kita untuk mengupload video, foto serta dapat mengirimkan pesan ke berbagai orang layaknya media sosial yang lain. Instagram sendiri memiliki fitur akun bisnis, private maupun publik. Seperti contohnya adalah akun-akun perusahaan game asal indonesia yang mendunia.

Pada penilitian ini, saya penulis akan menghitung menggunakan rasio-rasio yang ada di media sosial Instagram. Penulis hanya akan fokus menghitung rasio Image likes to followers. Adapun 5 akun perusahaan game asal Indonesia yang mendunia yang akan penulis jadikan sebagai acuan rasio tersebut adalah : Agate Studio, Megaxus, Gemscool, Garena, dan Touchten Games.

\section{B. TINJAUAN PUSTAKA}

Perkembangan teknologi informasi dan komunikasi sangatlah cepat, dimulai dari era sebelum digital yaitu menggunakan telegram sebagai komunikasi, sampai tibanya era digital dengan munculnya aplikasi-aplikasi serta platform media sosial. Sebagai contoh media sosial yang terkenal atau trending oleh masyarakat ini adalah instagram, tiktok, facebook, whatsapp, youtube, dsb. Aplikasi-aplikasi tersebut tidak hanya anak-anak muda yang menggunakannya, akan tetapi orang tua juga dapat menggunakannya.

Instagram adalah salah satu jenis media sosial dimana para penggunanya bisa mengunggah berbagai foto. Instagram dapat digunakan di gadget dengan sistem operasi iOS atau android sehingga si pengguna bisa lebih mudah mengunggah berbagai foto untuk diperlihatkan kepada orang lain. Selain itu Instagram juga memungkinkan penggunanya meng-upload video singkat yang bisa dilihat langsung oleh para followers (pengikutnya) (Gustina, 2015).

Melalui media sosial seperti Instagram ini seseorang menunjukan atau menampilkan dirinya kepada orang lain atau yang disebut dengan presentasi diri. Presentasi diri yang dilakukan dengan memanfaatkan media sosial Instagram ditampilkan dalam bentuk video singkat dan juga dalam bentuk foto. Dengan kata lain, individu menjadikan media sosial sebagai media presentasi diri (Rachmah, 2012) 
Kredibilitas suatu akun atau performa sebuah akun dalam instagram dapat kita ketahui dengan cara membandingkan rasio-rasio yang ada dalam instagram, sebagai contoh kita membandingkan rasio image likes dan followers, dari hasil analisis perbandingan rasio tersebut, kita dapat mengetahui apakah sebuah akun tersebut memiliki performa yang baik dibandingkan dengan yang lainnya

\section{METODE PENELITIAN}

Dalam penelitian ini, peneliti menggunakan metode eksploratif kuantitatif untuk mengetahui kredebilitas dari performa akun Instagram 5 Perusahaan Game Asal Indonesia Yang Mendunia. Metode eksploratif adalah sebuah metode penelitian dengan cara mengeksplor pengetahuan secara mendalam guna untuk merumuskan suatu penelitian secara terperinci (Maryam, Isrok'atun, and Aeni 2016).

Tujuan dari penelitian ini adalah untuk mengetahui kredebilitas performa dari akun Instagram yaitu 5 Perusahaan Game Asal Indonesia Yang Mendunia. Adapun untuk menentukan masing-masing peringkat dari 5 akun tersebut, peneliti akan menampilkan 4 langkah. Berikut adalah 4 langkah dalam menentukan peringkat:

\section{( Melakukan Eksplorasi Pada Website Untuk Menentukan Objek yang Akan Dianalisa.}

Hal pertama yang dilakukan adalah mengeksplorasi website yang menyediakan informasi tentang objek yang akan diteliti. Hasil eksplorasi diharapkan bisa memberikan informasi mengenai nama-nama 5 Perusahaan Game Asal Indonesia Yang Mendunia. Setelah mendapatkan nama-nama tersebut, langkah selanjutnya adalah mencari nama-nama 5 Perusahaan Game Asal Indonesia Yang Mendunia pada platform Instagram.

\section{(] Menghitung Nilai Rata-Rata Variable Dari Akun 5 Perusahaan Game Asal Indonesia Yang Mendunia.}

Langkah selanjutnya adalah peneliti menghitung nilai variable image likes dan variable followers. Variabel merupakan sesuatu yang memiliki nilai atau suatu medium yang dapat menampung nilai dari 4 jenis data yaitu, ordinal, skala, rasio dan nominal (Rankuti 2015). Dalam menemukan nilai rata-rata dari variable image likes to followers, kita perlu mengambil minimal 10 postingan dari ke 5 akun tersebut, lalu hitung sehingga mendapatkan nilai rata-rata dari masing-masing variabel. 


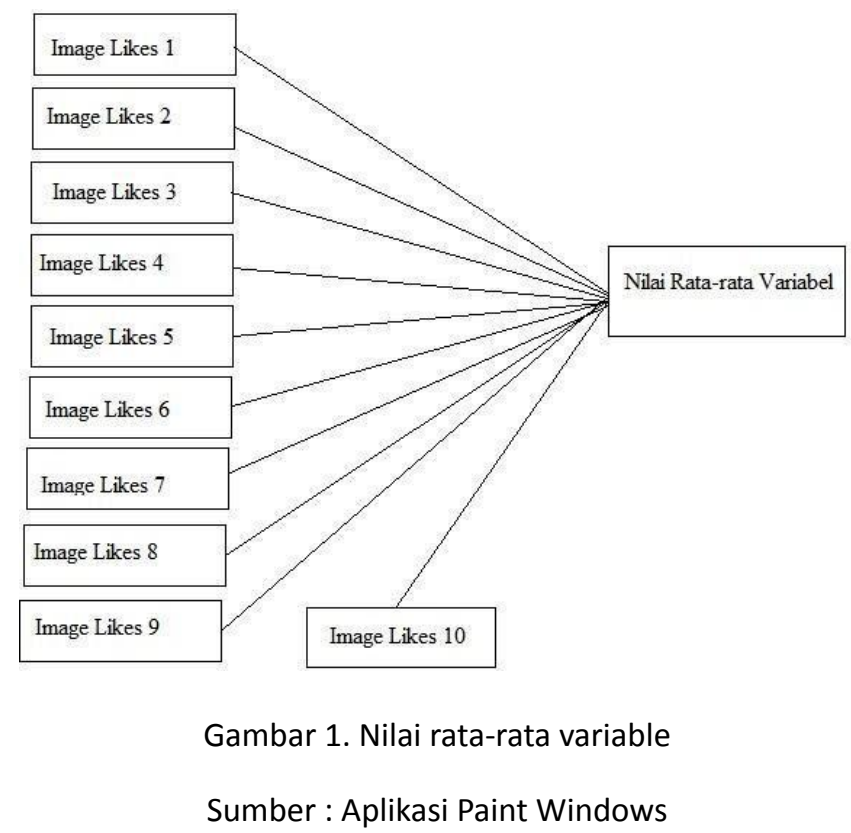

\section{(- Menghitung Nilai Kredibilitas Rasio}

Selanjutnya adalah menghitung kredibilitas dari image likes dan followers. Untuk menghitung nilai kredibilitas tersebut, peneliti membagi nilai variabel pertama dengan variabel kedua. Apabila image likes memiliki nilai 50 dan followers memiiki nilai 250, maka kita bagi nilai variabel pertama dengan kedua yaitu $90: 300=0.3$. Dengan begitu nilai kredibilitas dari image likes dan followers adalah 0.3 .

\section{Menentukan Peringkat Pada Akun Instagram}

Langkah terakhir adalah menentukan peringkat masing-masing rasio yang telah ada. Untuk menentukan masing-masing peringkat, peneliti perlu melihat karakteristik dari rasio yang diteliti. Apabila karakteristiknya rendah, maka objek dengan nilai terendah merupakan peringkat 1 . Sebaliknya, apabila karakteristiknya tinggi, maka nilai tertinggi merupakan peringkat 1 . 


\section{HASIL DAN PEMBAHASAN}

Akun Instagram dari 5 Perusahaan Game Asal Indonesia Yang Mendunia, diantaranya :

\section{Agate Studio}

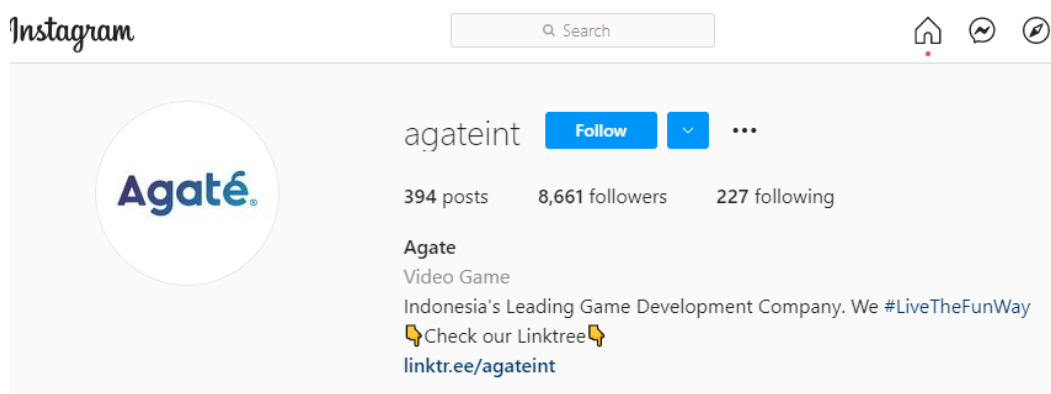

Gambar 2. Akun Instagram Oppo Indonesia

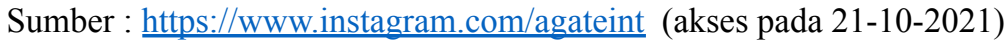

\section{Megaxus}

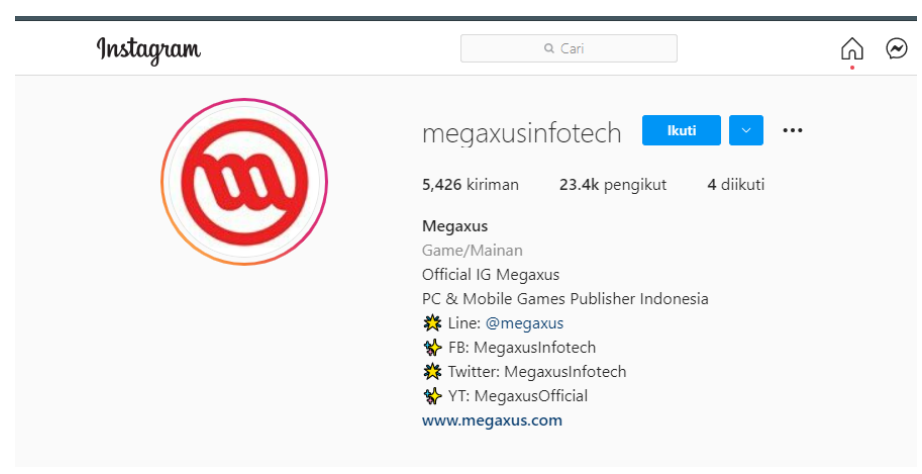

Gambar 3. Akun Instagram Samsung Indonesia

Sumber: https://www.instagram.com/megaxusinfotech (akses pada 21-10-2021)

\section{Garena}

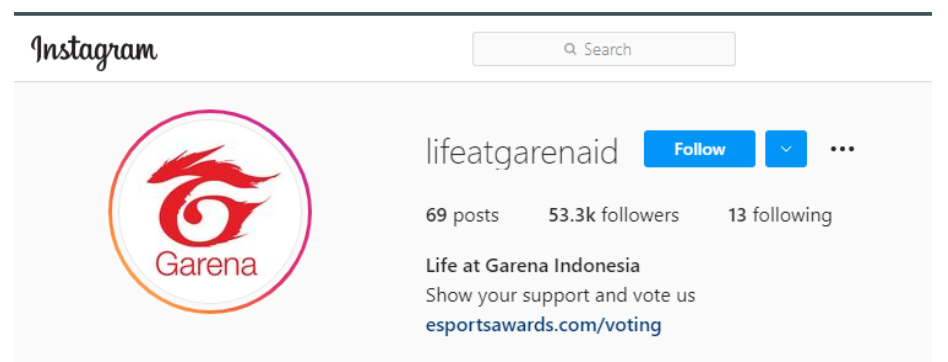

Gambar 4. Akun Instagram Vivo Indonesia

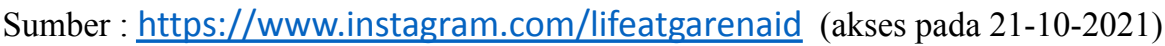




\section{Gemscool}

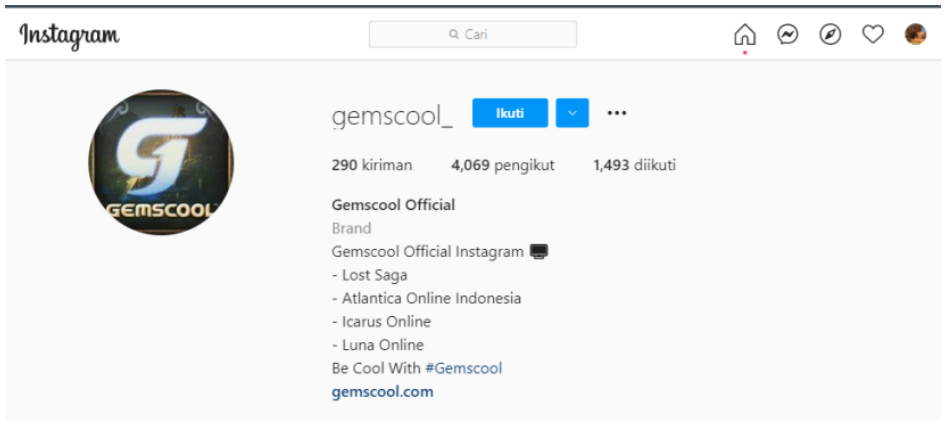

Gambar 5. Akun Instagram Xiaomi Indonesia

Sumber : https://www.instagram.com/gemscool (akses pada 21-10-2021)

\section{Touchten Games}

$\begin{array}{ll}\text { Instagram } & \text { touchtengames Follow } \\ & 332 \text { posts } 9,076 \text { followers } \\ \text { Touchten Games } \\ \text { We make awesome games for fun! Available on the App Store \& Google Play } \\ \text { Vote for us in \#IGA20, click the link below! \$8 } \\ \text { bit.ly/TouchtenIGA20 }\end{array}$

Gambar 6. Akun Instagram Touchten Games

Sumber : https://www.instagram.com/touchtengames/ (akses pada 21-10-2021)

Dari 5 akun diatas, peneliti menemukan nilai dari masing-masing variabel yang ada untuk menghitung rasio Image Likes to Followers pada setiap akun. Di Instagram sendiri, terdapat 8 variabel, yaitu :

1. Followers

2. Following

3. Video Likes

4. Video Comments

5. Video Views

6. Image Likes

7. Image Comments

8. Posts

Dari 8 variabel tersebut, kita akan fokus kepada 2 variabel saja, yaitu :

1. Image Likes 


\section{Followers}

Dari kedua variabel tersebut kemudian dianalisa sehingga menemukan nilai rata-rata dari variabel video comments dan variabel video views. Untuk menghitung nilai rata-rata dari variabel video comments dan variabel video views yaitu dengan cara mengambil minimal 10 postingan kemudian di hitung sehingga menemukan nilai rata-rata dari masing-masing variabel. Berikut merupakan tabel nilai rata-rata dari masing-masing vendor smartphone di Indonesia, yaitu :

Tabel 1. Analisa nilai rata-rata nilai Image Likes to Follower pada akun Instagram Agate Studio

\begin{tabular}{|c|r|r|}
\hline No & Image Likes & Followers \\
\hline 1 & 222 & 8.645 \\
\hline 2 & 45 & 8.645 \\
\hline 3 & 342 & 8.645 \\
\hline 4 & 126 & 8.645 \\
\hline 5 & 54 & 8.645 \\
\hline 6 & 209 & 8.645 \\
\hline 7 & 296 & 8.645 \\
\hline 8 & 160 & 8.645 \\
\hline 9 & 157 & 8.645 \\
\hline 10 & 278 & 8.645 \\
\hline Total & 189 & $\mathbf{8 . 6 4 5}$ \\
\hline
\end{tabular}

Sumber : Pengolah Data Excel

Tabel 2. Analisa nilai rata-rata nilai Image Likes to Follower pada akun Instagram Touchten Games

\begin{tabular}{|c|r|r|}
\hline No & Image Likes & Followers \\
\hline 1 & 45 & 9.081 \\
\hline 2 & 37 & 9.081 \\
\hline 3 & 31 & 9.081 \\
\hline 4 & 30 & 9.081 \\
\hline 5 & 128 & 9.081 \\
\hline 6 & 66 & 9.081 \\
\hline
\end{tabular}




\begin{tabular}{|c|r|r|}
\hline 7 & 54 & 9.081 \\
\hline 8 & 40 & 9.081 \\
\hline 9 & 34 & 9.081 \\
\hline 10 & 20 & 9.081 \\
\hline Total & 49 & 9.081 \\
\hline
\end{tabular}

Sumber : Pengolah Data Excel

Tabel 3. Analisa nilai rata-rata nilai Image Likes to Follower pada akun Instagram Gemscool Indonesia

\begin{tabular}{|c|r|r|}
\hline No & Image Likes & \multicolumn{1}{|c|}{ Followers } \\
\hline 1 & 320 & 4.077 \\
\hline 2 & 221 & 4.077 \\
\hline 3 & 306 & 4.077 \\
\hline 4 & 167 & 4.077 \\
\hline 5 & 157 & 4.077 \\
\hline 6 & 244 & 4.077 \\
\hline 7 & 165 & 4.077 \\
\hline 8 & 178 & 4.077 \\
\hline 9 & 296 & 4.077 \\
\hline 10 & 97 & 4.077 \\
\hline Total & 215 & 4.077 \\
\hline
\end{tabular}

Sumber : Pengolah Data Excel

Tabel 4. Analisa nilai rata-rata nilai Image Likes to Follower pada akun Instagram Megaxus

\begin{tabular}{|c|r|r|}
\hline No & Image Likes & Followers \\
\hline 1 & 17 & 23.400 \\
\hline 2 & 31 & 23.400 \\
\hline 3 & 79 & 23.400 \\
\hline
\end{tabular}




\begin{tabular}{|c|r|r|}
\hline 4 & 38 & 23.400 \\
\hline 5 & 21 & 23.400 \\
\hline 6 & 38 & 23.400 \\
\hline 7 & 19 & 23.400 \\
\hline 8 & 42 & 23.400 \\
\hline 9 & 47 & 23.400 \\
\hline 10 & 48 & 23.400 \\
\hline Total & $\mathbf{3 8}$ & $\mathbf{2 3 . 4 0 0}$ \\
\hline
\end{tabular}

Tabel 5. Analisa nilai rata-rata nilai Image Likes to Follower pada akun Instagram Garena Indonesia

\begin{tabular}{|c|r|r|}
\hline No & Image Likes & \multicolumn{1}{|c|}{ Followers } \\
\hline 1 & 48 & 53.000 \\
\hline 2 & 112 & 53.000 \\
\hline 3 & 282 & 53.000 \\
\hline 4 & 76 & 53.000 \\
\hline 5 & 118 & 53.000 \\
\hline 6 & 143 & 53.000 \\
\hline 7 & 265 & 53.000 \\
\hline 8 & 157 & 53.000 \\
\hline 9 & 184 & 53.000 \\
\hline 10 & 221 & 53.000 \\
\hline Total & 161 & 53.000 \\
\hline
\end{tabular}

Sumber : Pengolah Data Excel

Setelah menghitung nilai rata-rata , maka akan menemukan hasil akhir dari nilai rata-rata dari Image Likes to Followers. 
Tabel 6. Nilai rata-rata Image Likes to Follower pada akun 5 Perusahaan Game Asal Indonesia Yang Mendunia.

\begin{tabular}{|l|r|r|r|r|r|}
\hline \multicolumn{1}{|c|}{ Variable } & Ageta Studio & Garena & \multicolumn{1}{c|}{$\begin{array}{c}\text { Touchten } \\
\text { Games }\end{array}$} & Gemscool & Megaxus \\
\hline Image Likes & 189 & 161 & 49 & 215 & 38 \\
\hline Followers & 8645 & 53000 & 9081 & 2077 & 23400 \\
\hline
\end{tabular}

Sumber : Pengolah Data Excel

Tahapan selanjutnya adalah menghitung kredibilitas dari masing-masing akun instagram diatas, disini peneliti menghitung dengan cara : variabel 1 akan dibagi dengan variabel 2, sehingga ditemukan hasil nilai analisa dari rasio tersebut.

Tabel 7. Hasil Perhitungan Rasio Akun Instagram

\begin{tabular}{|c|l|c|c|c|c|c|}
\hline No & \multicolumn{1}{|c|}{ RATIO } & $\begin{array}{c}\text { Agate } \\
\text { Studio }\end{array}$ & Garena & Gemscool & $\begin{array}{c}\text { Touchten } \\
\text { Games }\end{array}$ & Megaxus \\
\hline 1 & $\begin{array}{l}\text { Image Likes to } \\
\text { Followers Ratio }\end{array}$ & 0,02186235 & 0,00303774 & 0,05273485 & 0,00539588 & 0,00162393 \\
\hline
\end{tabular}

Sumber : Pengolah Data Excel

Image Likes to Followers memiliki karakteristik yang tinggi, yang dimana artinya semakin tinggi nilai dari karaktersitik akun tersebut maka semakin baik nilai kredibilitas akun tersebut. Untuk memberikan peringkat dari masing-masing akun perusahaan game tersebut, peneliti memberikan nilai dari 1-5, dimana 1 adalah peringkat terendah, dan 5 adalah peringkat tertinggi. Berikut adalah urutan peringkat dari masing-masing akun instagram tersebut.

Tabel 8. Nilai Rasio akun Instagram 5 Perusahaan Game Asal Indonesia Yang Mendunia.

\begin{tabular}{|c|c|c|c|c|c|}
\hline \multirow{2}{*}{ RATIO } & \multicolumn{5}{|c|}{ NILAI } \\
\cline { 2 - 6 } & $\begin{array}{c}\text { Agate } \\
\text { Studio }\end{array}$ & Garena & Gemsool & $\begin{array}{c}\text { Touchten } \\
\text { Games }\end{array}$ & Megaxus \\
\hline $\begin{array}{c}\text { Image Likes to } \\
\text { Followers }\end{array}$ & 4 & 2 & 5 & 3 & 1 \\
\hline
\end{tabular}

Sumber : Pengolah Data Excel

Dari tabel rasio diatas, dapat kita simpulkan bahwa akun Instagram Gemscool merupakan akun dengan tingkat kredibilitas performa tertinggi, sementara akun Megaxus adalah akun dengan kredibilitas performa yang terendah. 


\section{E. KESIMPULAN}

Tujuan dari penelitian ini adalah mengetahui kredibilitas performa dari akun Instagram 5 Perusahaan Game Asal Indonesia Yang Mendunia dengan menggunakan rasio Image Likes to Followers. 5 Akun Perusahaan Game Asal Indonesia Yang Mendunia tersebut adalah : Agate Studio, Gemscool, Garena, Megaxus, dan Touchten Games. Dari kelima akun instagram tersebut dapat disimpulkan bahwa :

1. Peringkat pertama dipeganh oleh akun Gemscool dengan nilai rasio 0.05

2. Peringkat kedua diduki oleh Agate Studio dengan nilai rasio 0.02

3. Peringkat ketiga diduki oleh Garena dengan nilai rasio 0.03

4. Peringkat keempat diduki oleh Touchten Games dengan nilai rasio 0.0053

5. Peringkat kelima diduki oleh Megaxus dengan nilai rasio 0.0016.

\section{DAFTAR PUSTAKA}

Rachmah, Amy Julia. 2012. Pemanfaatan Situs Jejaring Sosial Sebagai Media Pembelajaraan. JEPTI (Jurnal Elektronik Pendidikan Teknik Informatika). Vol. 1. No.3. Bulan November 2012.

Gustina, Henry. 1970. Korelasi Media Sosial Instagram Dengan Presentasi Diri Mahasiswa Jurusan Ilmu Komunikasi Universitas Riau. Vol. 2. No.2.

Rankuti, Freddy. 2015. “Buku Riset Pemasaran.” 2015.

Maryam, Siti, Isrok'atun Isrok'atun, and Ani Nur Aeni. 2016. 'PENDEKATAN

EKSPLORATIF UNTUK MENINGKATKAN KEMAMPUAN REPRESENTASI

MATEMATIS DAN KEPERCAYAAN DIRI SISWA.”Jurnal Pena Ilmiah 1 (1): 551-60. https://doi.org/10.23819/PI.V1I1.2984.

5 Perusahaan Game Asal Indonesia Yang Mendunia." n.d. Accessed October 21, 2021. https://economy.okezone.com/read/2019/06/28/320/2072187/5-perusahaan-game-asalindonesia-yang-mendunia. 